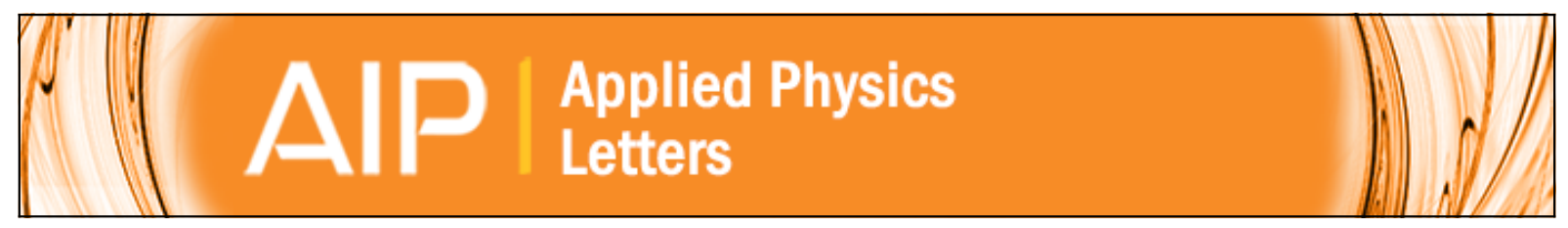

\title{
Observation of oxide precipitates in InN nanostructures
}

Soon-Yong Kwon, Zaiyuan Ren, Qian Sun, Jung Han, Young-Woon Kim, Euijoon Yoon, Bo Hyun Kong, Hyung

Koun Cho, Il-Joong Kim, and Hyeonsik Cheong

Citation: Applied Physics Letters 91, 234102 (2007); doi: 10.1063/1.2822396

View online: http://dx.doi.org/10.1063/1.2822396

View Table of Contents: http://scitation.aip.org/content/aip/journal/apl/91/23?ver=pdfcov

Published by the AIP Publishing

\section{Articles you may be interested in}

Selective-hydrogen sensing at room temperature with Pt-coated InN nanobelts

Appl. Phys. Lett. 93, 202109 (2008); 10.1063/1.3033548

High-density InGaN nanodots grown on pretreated GaN surfaces

Appl. Phys. Lett. 89, 023114 (2006); 10.1063/1.2218312

Near-red emission from site-controlled pyramidal InGaN quantum dots

Appl. Phys. Lett. 87, 163121 (2005); 10.1063/1.2108126

InGaN nanorings and nanodots by selective area epitaxy

Appl. Phys. Lett. 87, 143111 (2005); 10.1063/1.2056584

Characterization of oxide precipitates in epitaxial InN by transmission electron microscopy

Appl. Phys. Lett. 87, 092102 (2005); 10.1063/1.2035330

\section{AlP $\mid$ Applied Physics}

AlPetters

is pleased to announce Reuben Collins as its new Editor-in-Chief

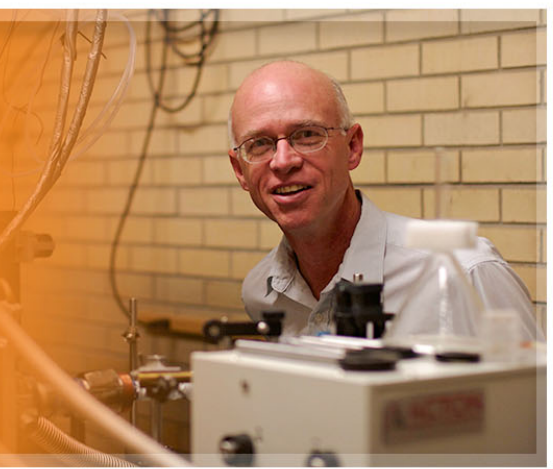




\title{
Observation of oxide precipitates in InN nanostructures
}

\author{
Soon-Yong Kwon, ${ }^{\text {a) }}$ Zaiyuan Ren, Qian Sun, and Jung Han \\ Department of Electrical Engineering, Yale University, New Haven, Connecticut 06520, USA \\ Young-Woon Kim and Euijoon Yoon \\ Department of Materials Science and Engineering, Seoul National University, Seoul 151-742, Korea
}

Bo Hyun Kong and Hyung Koun Cho

School of Advanced Materials Science and Engineering, Sungkyunkwan University, Suwon 440-746, Korea

II-Joong Kim and Hyeonsik Cheong

Department of Physics, Sogang University, Seoul 121-742, Korea

(Received 31 August 2007; accepted 16 November 2007; published online 5 December 2007)

\begin{abstract}
We observed the formation of oxide precipitates $\left(\mathrm{bcc}-\mathrm{In}_{2} \mathrm{O}_{3}\right)$ in $\mathrm{InN}$ nanostructures formed during metal-organic chemical vapor deposition (MOCVD) and/or subsequent postgrowth procedures in $\mathrm{H}_{2}$ ambient. It was found that $\mathrm{InN}$ is extremely unstable in $\mathrm{H}_{2}$ ambient and the activation energy of $\mathrm{N}_{2}$ desorption of $\mathrm{InN}$ is measured to be $\sim 0.28 \mathrm{eV}$, which is one order of magnitude smaller than that of reported value of $\mathrm{InN}$ in vacuum. Instability of $\mathrm{InN}$ nanostructures under $\mathrm{H}_{2}$ ambient together with residual oxidant in the reactor facilitates the formation of indium oxide precipitates in the nanostructure matrix during MOCVD or the oxidation of residual indium at the surface, resulting in indium oxide dots. (C) 2007 American Institute of Physics. [DOI: 10.1063/1.2822396]
\end{abstract}

Indium nitride ( $\mathrm{InN})$ has attracted much attention recently as an important group III-nitride semiconductor. ${ }^{1} \mathrm{Al}-$ though thermal instability of InN as well as large lattice and thermal mismatches make the growth of InN films extremely difficult, ${ }^{1}$ recent results on InN-based nanostructures ${ }^{2-4}$ are very promising and indicative of potential device applications. However, depending on the growth conditions, there is a possibility of oxide precipitation in such $\mathrm{InN}$ nanostructures during growth and/or postgrowth procedures because of high volatility of $\mathrm{N}_{2}$ from InN surface ${ }^{1,2}$ and high tendency for indium residue on surface to react with background molecular oxygen. ${ }^{5}$ It is expected that oxidation would easily occur for indium residue on surface in preference to nitridation by considering the large difference in the heat of formation of $\mathrm{InN}(34 \mathrm{kcal} / \mathrm{mol}){ }^{6}$ compared with $\mathrm{In}_{2} \mathrm{O}_{3}$ (221 kcal/mol). ${ }^{5}$ Generally, InN is grown with $\mathrm{N}_{2}$ carrier gas or a mixed carrier gas of $\mathrm{N}_{2}$ and $\mathrm{H}_{2}$ in metal-organic chemical vapor deposition (MOCVD) because of expected thermal instability of InN under $\mathrm{H}_{2}$ ambient. ${ }^{7} \mathrm{Up}$ to date, there are a few empirical information on this specificity in the growth of InGaN; $;{ }^{8,9}$ however, the role of hydrogen is unclear and speculative in these reports. Therefore, it is desirable to investigate the role of hydrogen in detail in MOCVD growth of InN because hydrogen and hydrogen-containing derivatives are present during $\mathrm{InN}$ growth and it will provide a deeper understanding of the underlying chemistry. In this letter, we report the observation of oxide precipitates (bcc- $\mathrm{In}_{2} \mathrm{O}_{3}$ ) in $\mathrm{InN}$ nanostructures formed during MOCVD and/or postgrowth procedures in $\mathrm{H}_{2}$ ambient. InN was extremely unstable in $\mathrm{H}_{2}$ ambient and the appearance of oxide precipitates was very similar to that expected from genuine InN nanostructures, rendering a possibility of false detection.

Two sets of InN nanostructures were grown in commercial horizontal MOCVD reactors. Trimethylgallium, trimeth-

\footnotetext{
${ }^{a}$ Author to whom correspondence should be addressed. Electronic mail:
} syong.kwon@gmail.com. ylindium (TMIn), and ammonia $\left(\mathrm{NH}_{3}\right)$ were used as $\mathrm{Ga}$, In, and $\mathrm{N}$ sources, respectively, whereas both high-purity $\mathrm{H}_{2}$ and $\mathrm{N}_{2}$ of $6 \mathrm{~N}(99.9999 \%)$ were used as carrier gases. Hydrogen was further purified by a Pd purifier. The first set of $\mathrm{InN}$ nanostructures was grown on top of 20-nm-thick cubic GaN $(c-\mathrm{GaN}) / \mathrm{GaP}(100)$ templates grown at $520{ }^{\circ} \mathrm{C}$ in $\mathrm{H}_{2}$ ambient. The InN dots were grown at growth temperatures in the range of $450-550{ }^{\circ} \mathrm{C}$ and the growth pressure was 200 mbar. $\mathrm{H}_{2}$ carrier gas (7.0 SLM) was introduced throughout the InN growth with $\mathrm{NH}_{3}$ (3.75 SLM), where SLM stands for standard liters per minute. Immediately after the InN growth, $\mathrm{H}_{2}$ carrier gas was replaced with $\mathrm{N}_{2}$ and both $\mathrm{N}_{2}$ carrier gas (7.0 SLM) and $\mathrm{NH}_{3}(3.75 \mathrm{SLM})$ were introduced during cooling process to room temperature (RT). The growth rate of $\mathrm{InN}$ dots was controlled by TMIn flow rate. The TMIn flow rates were 7.5 and $15 \mu \mathrm{mol} / \mathrm{min}$, and the corresponding growth times were 45 and $22.5 \mathrm{~min}$, respectively, to keep the total amount of deposition from the gasphase sources constant in all $\mathrm{InN}$ growth at a certain growth temperature. The second set of InN nanostructures is a few monolayer (ML)-thick InN epitaxial layers grown on $2-\mu \mathrm{m}$-thick GaN/sapphire(0001) templates. The growth of $\mathrm{InN}$ was performed at $730{ }^{\circ} \mathrm{C}$ for $90 \mathrm{~s}$ and the growth pressure was 300 Torr. All growth conditions were fixed, and TMIn $(10 \mu \mathrm{mol} / \mathrm{min})$ and $\mathrm{NH}_{3}(4.0 \mathrm{SLM})$ were supplied as precursors and $\mathrm{N}_{2}$ carrier gas (3.6 SLM) was used. After the $\mathrm{InN}$ growth, we varied the cooling environment, one is to keep flowing $\mathrm{N}_{2}$ carrier gas (3.6 SLM) and $\mathrm{NH}_{3}$ (4.0 SLM), while the samples was cooled down to RT, and the other is to keep flowing $\mathrm{N}_{2}$ carrier gas and $\mathrm{NH}_{3}$ down to $400{ }^{\circ} \mathrm{C}$, followed $\mathrm{H}_{2}$ carrier gas (7.6 SLM) down to RT.

Figure 1(a) shows a cross-section transmission electron microscope (TEM) image taken for $\mathrm{InN}$ dots grown on a $c$ - GaN/GaP(100) template at $450{ }^{\circ} \mathrm{C}$ with TMIn flow rate of $15 \mu \mathrm{mol} / \mathrm{min}$. The indexing of the diffraction pattern (DP) taken from overall structures (not shown here) proved that $\mathrm{InN}$ dots grow in zinc-blende structure, where $c-\operatorname{InN}(100)$ 


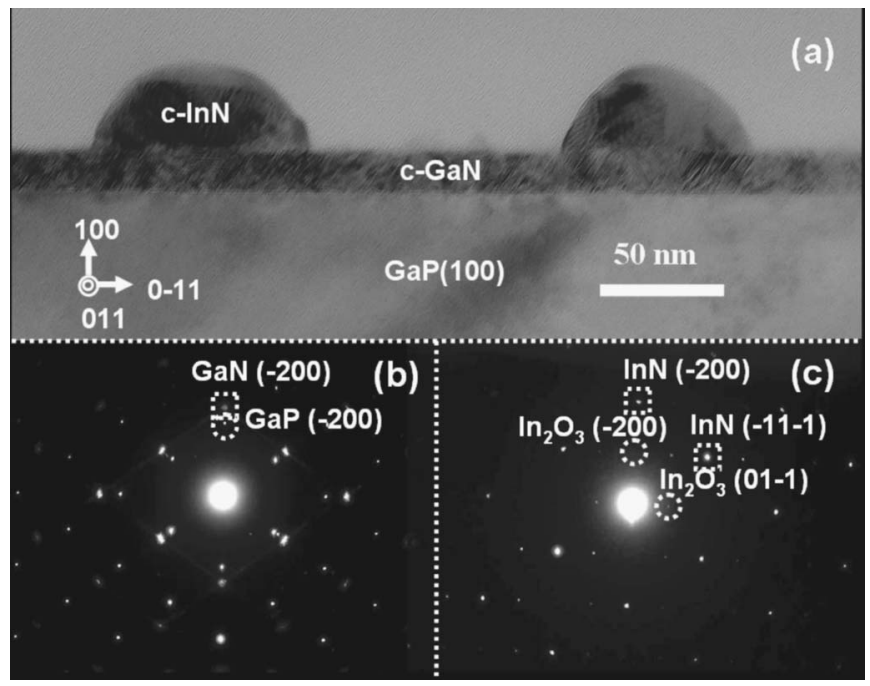

FIG. 1. (a) Cross-section TEM image of InN dots grown at $450{ }^{\circ} \mathrm{C}$ with TMIn flow rate of $15 \mu \mathrm{mol} / \mathrm{min}$ on 20 -nm-thick $c$-GaN/GaP(100), (b) SADP of the interface between $c-G a N$ buffer (square) and $\mathrm{GaP}(100)$ substrate (circle), and (c) SADP of the InN dot (square) with coexisting precipitates bcc- $\operatorname{In}_{2} \mathrm{O}_{3}$ (circle).

planes are parallel to $c$ - $\mathrm{GaN}(100)$ planes and hexagonal $\mathrm{InN}$ is not present. However, an additional set of diffraction spots was found in this sample. We obtained selective area DPs (SADPs) to determine where they were originated and the additional set of diffraction spots was found only from $\mathrm{InN}$ dots, as shown in Figs. 1(b) and 1(c). Based on the corresponding angles and distances between the spots, the coexisting precipitates in $\mathrm{InN}$ dots were determined as body centered cubic (bcc)- $\operatorname{In}_{2} \mathrm{O}_{3}$. The oxide precipitates were uniformly distributed from the central to the edge area of $\mathrm{InN}$ dots from SADP, and it is reasonable to assume that the oxidation process occurred during MOCVD rather than postgrowth process. We supposed that this phenomenon is related to low thermal stability of $\mathrm{InN}$ in $\mathrm{H}_{2}$ ambient since hydrogen tends to etch $\mathrm{InN}$ and reduces nitrogen sticking coefficient in $\operatorname{In}(\mathrm{Ga}) \mathrm{N}$, as predicted by thermodynamic calculations. ${ }^{7}$

This hypothesis was tested by growing $\mathrm{InN}$ dots with $\mathrm{H}_{2}$ carrier gas on $c-\mathrm{GaN} / \mathrm{GaP}(100)$ templates at a constant amount of deposition from the gas-phase sources but at different temperatures and growth rates. Growth temperatures were varied from 450 to $550{ }^{\circ} \mathrm{C}$ and the calculation of growth rate of InN dots was based on the assumption that the shape of InN dots was a perfect hemisphere. The results are shown in Fig. 2. Higher growth temperature leads to lower growth rate, indicating the strong thermal decomposition of InN during growth, and the activation energy is measured to be $\sim 0.28 \mathrm{eV}$ on the Arrhenius plot. This value is one order of magnitude smaller than the reported activation energy of $\mathrm{N}_{2}$ desorption of $\mathrm{InN}$ (or $\mathrm{GaN}$ ) in vacuum. ${ }^{10,11}$ Based on this result, we concluded that the introduction of $\mathrm{H}_{2}$ into the reactor greatly lowered the thermal stability of InN, which enhances the possibility of oxidation of InN.

We also find that surface oxidation of preexisting $\mathrm{InN}$ can occur depending on how growth was terminated. A few ML-thick InN was grown on 2 - $\mu$ m-thick GaN/ sapphire(0001) template with typical step-flow like feature of atomically flat surface to see the surface morphology of the bare InN layer. After $90 \mathrm{~s}$ InN deposition, the sample was cooled down to RT with both $\mathrm{N}_{2}$ and $\mathrm{NH}_{3}$ flows and the

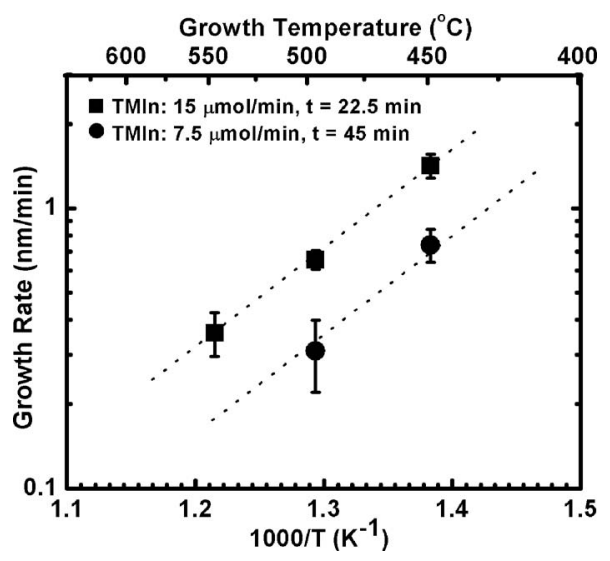

FIG. 2. Arrhenius plot of $\mathrm{N}_{2}$ desorption-controlled growth rate of InN dots vs. substrate temperature at a constant amount of deposition from the gasphase sources.

resulting sample surface showed the stepped twodimensional (2D) morphology with the formation of 2D disk-shaped structures on terraces, as shown in Fig. 3(a). Heights of 2D disk-shaped structures were about 3-5 $\AA$ as measured by atomic force microscopy (AFM), which are equivalent to $1-2 \mathrm{ML}$ of $\mathrm{InN}$ and their diameters were less than $200 \mathrm{~nm} .{ }^{12}$ However, when $\mathrm{N}_{2}$ carrier gas and $\mathrm{NH}_{3}$ were switched off at $400{ }^{\circ} \mathrm{C}$ and the $\mathrm{InN}$ specimen was cooled down to RT under $\mathrm{H}_{2}$ ambient, the surface morphology of $\mathrm{InN}$ was greatly changed. The quantum dot (QD)-like structures with a density of $2.5 \times 10^{9} \mathrm{~cm}^{-2}$ surprisingly appeared on InN surface and most of them existed on 2D disk-shaped structure from AFM measurement, as shown in Fig. 3(b).

From the cross-section TEM images, as shown in Fig. 4, the QD-like structures on InN surface have a different lattice image from underlying GaN template and it turns out to be bcc- $\operatorname{In}_{2} \mathrm{O}_{3}$ instead of InN. The interplanar spacing of high resolution lattice fringe image of $\mathrm{In}_{2} \mathrm{O}_{3}$ was $\sim 2.9 \AA$ and this corresponds to the reported lattice constant of bcc- $\operatorname{In}_{2} \mathrm{O}_{3}(222),{ }^{13}$ which is in good agreement with a preferential orientation of $\operatorname{In}_{2} \mathrm{O}_{3}$ formed by thermal oxidation of InN. ${ }^{14}$ We believe that decomposition and desorption of $\mathrm{N}_{2}$ from InN surface were greatly enhanced under $\mathrm{H}_{2}$ ambient during cooling process and the indium residue on the surface would strongly chemisorb background molecular oxygen, ${ }^{5}$ resulting in bcc- $\operatorname{In}_{2} \mathrm{O}_{3}$ formation mainly on $2 \mathrm{D}$ disk-shaped structures.

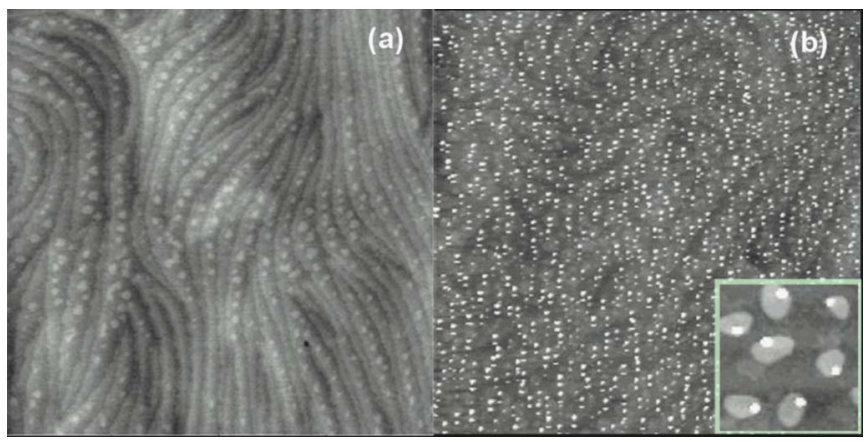

FIG. 3. (Color online) $4 \times 4 \mu \mathrm{m}^{2} \mathrm{AFM}$ images of a few ML-thick InN layers on $\mathrm{GaN}$ templates with a cooling environment of (a) $\mathrm{N}_{2}$ carrier gas and $\mathrm{NH}_{3}$ to $\mathrm{RT}$ and (b) $\mathrm{N}_{2}$ carrier gas and $\mathrm{NH}_{3}$ down to $400{ }^{\circ} \mathrm{C}$, followed by only $\mathrm{H}_{2}$ carrier gas down to $\mathrm{RT}$. The inset depicts the formation of QD-like structures mostly on 2D disk-shaped structures. 


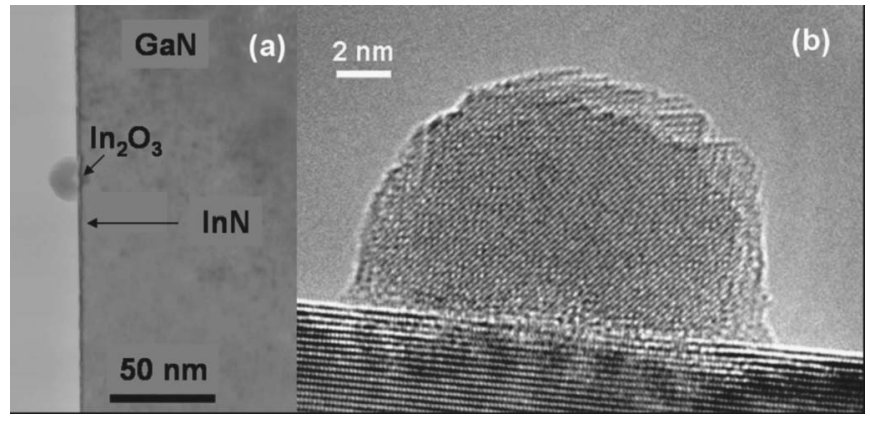

FIG. 4. (a) Cross-section TEM image of bcc- $\operatorname{In}_{2} \mathrm{O}_{3}$ formed on InN layer and (b) high resolution image of (a).

It is noteworthy that the oxidation of $\mathrm{InN}$ during MOCVD growth and/or subsequent postgrowth procedures would be a problem that must be taken into account during InN-based device fabrication. By considering the heats of formation of $\mathrm{InN}(34 \mathrm{kcal} / \mathrm{mol})$ (Ref. 6) and $\operatorname{In}_{2} \mathrm{O}_{3}$ $(221 \mathrm{kcal} / \mathrm{mol}),{ }^{5}$ the very small amount of background oxygen or water vapor existing in the reactor can lead to the detectable oxidation of InN. Even if InN growth is performed in an inert gas environment such as $\mathrm{N}_{2}$, there is still a possibility of oxidation of $\mathrm{InN}$ since the hydrogencontaining derivatives from the decomposition of $\mathrm{NH}_{3}$ (Ref. 7) and/or $\mathrm{H}_{2}$ carrier gas introduced for the subsequent (Al)GaN growth can influence the thermal stability of preexisting InN nanostructures. We finally note that, as the size of InN is getting smaller, the possibility of false detection of oxide precipitates as InN dots, when an inappropriate ambient was provided, is getting larger by nominal characterization tools because of their structural similarity.

In conclusion, it was found that $\mathrm{InN}$ nanostructures are extremely sensitive to growth environment. $\mathrm{InN}$ is very unstable especially in $\mathrm{H}_{2}$ ambient and the activation energy of $\mathrm{N}_{2}$ desorption from $\mathrm{InN}$ in hydrogen ambient is measured to be $\sim 0.28 \mathrm{eV}$. The appearance of oxide precipitates was very similar to that expected from genuine InN nanostructures.
This work was supported by the DOE-NEFL Project. The work at Sogang was supported in part by the MOST/ KOSEF through the Quantum Photonic Science Research Center. S.Y.K. acknowledges the support of the Korea Research Foundation Grant funded by Korea Government (MOEHRD, Basic Research Promotion Fund) (No. KRF2005-214-D00315). E.Y. acknowledges the support from Center for Materials and Processes of Self-Assembly through MOST/KOSEF (No. R11-2005-048-00000-0).

${ }^{1}$ A. G. Bhuiyan, A. Hashimoto, and A. Yamamoto, J. Appl. Phys. 94, 2779 (2003).

${ }^{2}$ S.-Y. Kwon, H. J. Kim, H. Na, Y.-W. Kim, H.-C. Seo, H. J. Kim, Y. Shin, E. Yoon, and Y.-S. Park, J. Appl. Phys. 99, 044906 (2006).

${ }^{3}$ A. Yoshikawa, N. Hashimoto, N. Kikukawa, S. B. Che, and Y. Ishitani, Appl. Phys. Lett. 86, 153115 (2005).

${ }^{4}$ S. Ruffenach, B. Maleyre, O. Briot, and B. Gil, Phys. Status Solidi C 2, 826 (2005).

${ }^{5}$ B. R. Natarajan, A. H. Eltoukhy, J. E. Greene, and T. L. Barr, Thin Solid Films 69, 217 (1980).

${ }^{6}$ J. B. MacChesney, P. M. Bridenbaugh, and P. B. O'Connor, Mater. Res. Bull. 5, 783 (1970).

${ }^{7}$ A. Koukitu, T. Taki, N. Takahasi, and H. Seki, J. Cryst. Growth 197, 99 (1999).

${ }^{8}$ F. Scholz, V. Härle, F. Steuber, H. Bolay, A. Dörnen, B. Kaufmann, V. Syganow, and A. Hangleiter, J. Cryst. Growth 170, 321 (1997).

${ }^{9}$ E. L. Piner, M. K. Behbehani, N. A. El-Masry, F. G. McIntosh, J. C. Roberts, K. S. Boutros, and S. M. Bedair, Appl. Phys. Lett. 70, 461 (1997).

${ }^{10}$ D. D. Koleske, A. E. Wickenden, R. L. Henry, M. E. Twigg, J. C. Culbertson, and R. J. Gorman, Appl. Phys. Lett. 73, 2018 (1998).

${ }^{11}$ O. Ambacher, M. S. Brandt, R. Dimitrov, T. Metzger, M. Stutzmann, R. A. Fischer, A. Miehr, A. Bergmaier, and G. Dollinger, J. Vac. Sci. Technol. B 14, 3532 (1996).

${ }^{12}$ H. J. Kim, H. Na, S.-Y. Kwon, H.-C. Seo, H. J. Kim, Y. Shin, K.-H. Lee, Y.-W. Kim, S. Yoon, H. J. Oh, C. Sone, Y. Park, Y.-H. Cho, Y. Sun, and E. Yoon, Phys. Status Solidi C 0, 2834 (2003).

${ }^{13}$ JCPDS Card No. 06-0416, 1998.

${ }^{14}$ S. Luo, W. Zhou, Z. Zhang, J. Shen, L. Liu, W. Ma, X. Zhao, D. Liu, L. Song, Y. Xiang, J. Zhou, S. Xie, and W. Chu, Appl. Phys. Lett. 89, 093112 (2006). 